\title{
The association between molecular type and prognosis of patients with stage IV breast cancer: an observational study based on SEER database
}

\author{
Lingmi Hou ${ }^{1,2 \#}$, Mengxue Qiu ${ }^{3 \#}$, Maoshan Chen ${ }^{3,4 \#}$, Fangfang $\mathrm{Li}^{4}$, Junyan $\mathrm{Li}^{5}$, Shishan Deng ${ }^{1}$, Yahan \\ Yang $^{6}$, Zhenggui $\mathrm{Du}^{3}$, Hongwei Yang ${ }^{4}$
}

${ }^{1}$ Department of Breast and Thyroid Surgery, Biological Targeting Laboratory of Breast Cancer, Academician (expert) Workstation, Affiliated Hospital of North Sichuan Medical College, Nanchong, China; ${ }^{2}$ Yingshan Hospital of West China Hospital, Sichuan University, Nangchong, China; ${ }^{3}$ Department of Breast Surgery, West China Hospital, Sichuan University, Chengdu, China; ${ }^{4}$ Department of Breast and Thyroid Surgery, Affiliated Suining Central Hospital of Chongqing Medical University, Suining, China; ${ }^{5}$ Department of Breast Surgery, People's Hospital of Deyang City, Deyang, China; ${ }^{6}$ Clinical Medicine, Queen Mary College of Nanchang University, Nanchang, China

Contributions: (I) Conception and design: M Chen, H Yang; (II) Administrative support: L Hou, M Chen, M Qiu; (III) Provision of study materials or patients: Y Yang, F Li, S Deng; (IV) Collection and assembly data: L Hou, F Li, J Li; (V) Data analysis and interpretation: Z Du, F Li, M Chen, L Hou, H Yang; (VI) Manuscript writing: All authors; (VII) Final approval of manuscript: All authors.

\#These authors contributed equally to this work.

Correspondence to: Zhenggui Du, MD, PhD. Department of Breast Surgery and Thyroid Surgery, West China Hospital, Sichuan University, 37 Guoxue Street, Wuhou District, Chengdu 610041, China. Email: docduzg@163.com; Hongwei Yang, MD. Department of Breast and Thyroid Surgery, Affiliated Suining Central Hospital of Chongqing Medical University, 127 Desheng West Road, Chuanshan District, Suining 629000, China. Email: yhwsnch@163.com.

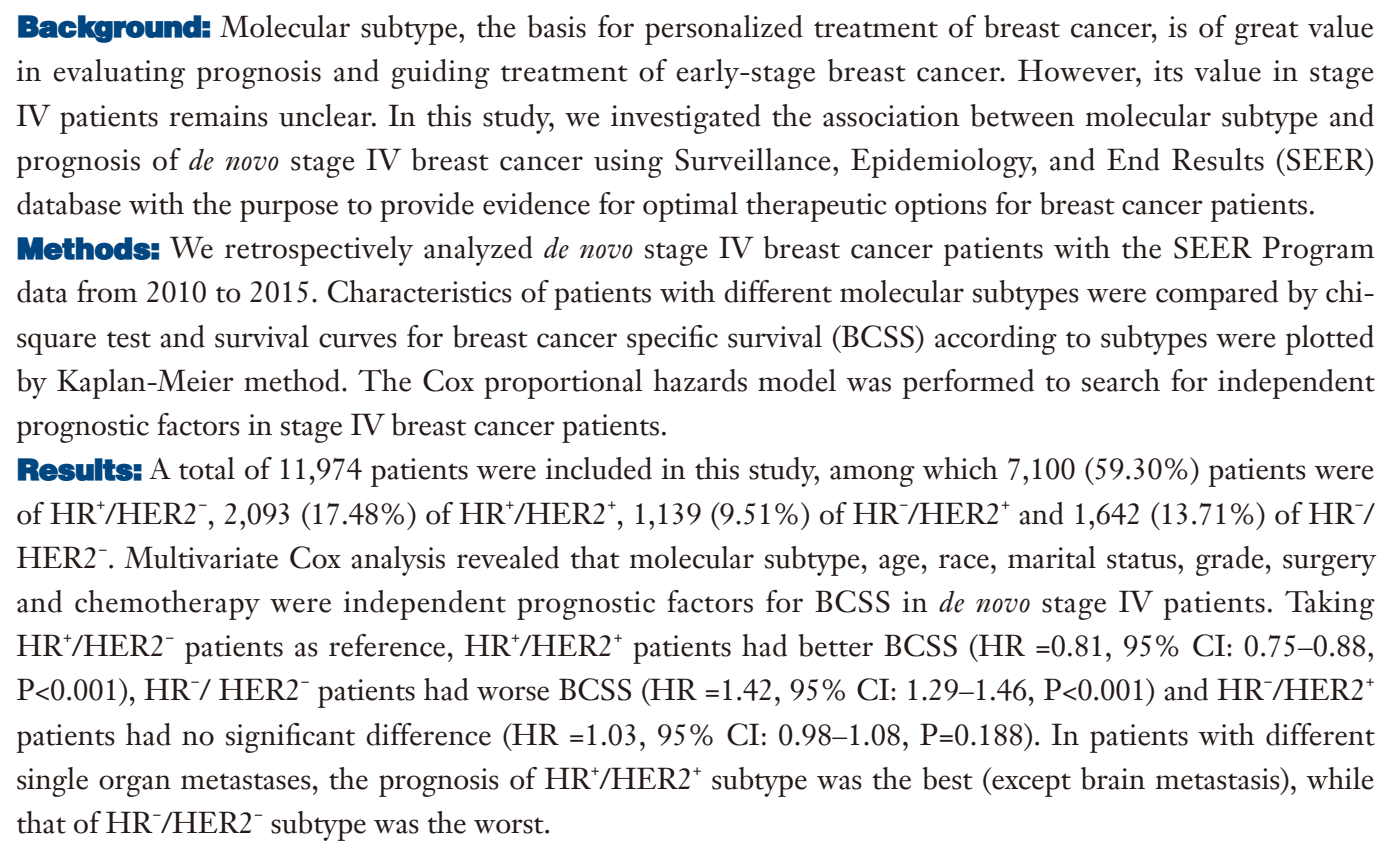

Conclusions: Molecular subtypes were closely associated with the prognosis of de novo stage IV breast cancer. Among the four subtypes, $\mathrm{HR}^{+} / \mathrm{HER}^{+}$patients had the best prognosis while $\mathrm{HR}^{-} / \mathrm{HER}^{-}$patients had the worst. The prognosis of patients with different single organ metastases was the same, but in patients

^ ORCID: 0000-0002-9164-6346. 
with brain metastases, $\mathrm{HR}^{+} / \mathrm{HER} 2^{+}$ones did not have a significantly better prognosis than other subtypes except triple-negative type.

Keywords: Molecular type; breast cancer; stage IV; prognosis; Surveillance, Epidemiology, and End Results program (SEER program)

Submitted Jan 16, 2021. Accepted for publication May 11, 2021.

doi: $10.21037 / g s-21-32$

View this article at: https://dx.doi.org/10.21037/gs-21-32

\section{Introduction}

Breast cancer has become the most common malignant tumor in women, among which the de novo stage IV breast cancer accounts for about $3-10 \%$ of total initially diagnosed cases (1-3). This type of breast cancer is incurable with a poor prognosis as 5 -year survival rate is only $25 \%$ (4). In order to improve quality and prolong the length of patients' life as much as possible, the therapy in stage IV breast cancer usually focuses on systemic comprehensive treatment (4-6). At present, the treatment of breast cancer has entered the era of molecular subtype-based personal therapeutics. According to the classification by hormone receptor (HR) status and human epidermal growth factor receptor-2 (HER2), breast cancer can be divided into $\mathrm{HR}^{+} / \mathrm{HER} 2^{-}$, $\mathrm{HR}^{+} / \mathrm{HER}^{+}{ }^{+}, \mathrm{HR}^{-} / \mathrm{HER} 2^{-}$and $\mathrm{HR}^{-} / \mathrm{HER} 2^{+}$subtypes (7-9). The molecular subtype was found to be useful for evaluating prognosis and guiding treatment in early-stage breast cancer patients by effectively reflecting biological characteristics of tumor and predicting the sensitivity of treatment to a certain extent (10). However, the relationship between molecular subtype and prognosis remains to be studied in de novo stage IV patients (11). Andre et al. (12) noted that $\mathrm{HR}^{-}$, multiple site metastasis, visceral involvement and so on were risk factors for prognosis of $d e$ novo stage IV patients, and Cortesi et al. (13) stated that the 5 -year overall survival (OS) was significantly increased for $\mathrm{HR}^{+}$and HER2 ${ }^{+}$tumors. Although stage IV breast cancer is incurable, classification based on molecular subtype can provide patients with treatment alternatives for better survival rate. The results of our study could give proof and guidance to clinical application of molecular subtype in evaluating prognosis of stage IV breast cancer and provide reference data for clinical treatment.

The Surveillance, Epidemiology, and End Results (SEER) database of the National Cancer Institute is a coordinated system of population-based cancer registries that collects cancer incidence and survival data from 18 geographic regions in United States representing approximately $28 \%$ of the country's total land areas. In this study, we retrospectively analyzed de novo stage IV breast cancer patients using SEER Program data from 2010 to 2015 to investigate the interaction between molecular type and prognosis of patients. We present the following article in accordance with the STROBE reporting checklist (available at https://dx.doi.org/10.21037/gs-21-32).

\section{Methods}

\section{Data collection}

De novo stage IV breast cancer cases were extracted from the SEER database. Inclusion criteria are: (I) female cases; (II) no age limitation; (III) pathological diagnosis; (IV) within the year range from 2010 to 2015; (V) TNM stage as IV. Exclusion criteria are: (I) multiple sites of tumors origins; (II) absence of survival data. Eventually, 11,974 patients were included in the study.

A list with included cases was generated with the data updated in November 2018 from the SEER*Stat version 8.3.5. The data of year, age at diagnosis, race, marital status, tumor site, histological grade, HR, HER2, American Joint Committee on Cancer (AJCC) stage group 7th edition, surgical operation, chemotherapy, radiotherapy, survival time and survival outcome were extracted. HR includes estrogen receptor (ER) and progesterone receptor (PR), the positivity of which is defined as ER or PR positive. According to HR and HER2 status, 11,974 patients were divided into four molecular subtypes: 7,100 (59.30\%) patients of $\mathrm{HR}^{+} / \mathrm{HER}^{-}, 2,093$ (17.48\%) of $\mathrm{HR}^{+} / \mathrm{HER}^{+}, 1,139$ (9.51\%) of $\mathrm{HR}^{-} / \mathrm{HER}^{+}$and $1,642(13.71 \%)$ of $\mathrm{HR}^{-} / \mathrm{HER} 2^{-}$.

\section{Statistical analysis}

In this study, breast cancer specific survival (BCSS) was used to evaluate the prognosis of patients. BCSS was defined as 
the interval (month termed) between the time of diagnosis and end of follow-up or time of death, and data of nonbreast cancer-related deaths were excluded for analysis. By comparing BCSS among patients with different molecular subtypes, the association between molecular subtype and prognosis of de novo stage IV breast cancer was analyzed.

Stata 13.0/MP software was used for statistical analysis. Data with continuous variables were presented as median [interquartile range (IQR)], and data with categorical variables were presented as percentages. The characteristics of different molecular subtypes patients were compared by chi-square test and survival curves were plotted by KaplanMeier method. Cox analysis was performed to screen factors governing prognosis in de novo stage IV patients. Parameters with a statistical significance in univariate Cox analysis were included in the multivariate Cox model. The adjusted hazard ratios (HRs) and corresponding 95\% confidence intervals (CIs) were calculated in multivariate model. The factors included in the prognostic analysis were molecular subtype, age, race, marital status, histology, grade, lymph node stage, surgery and radiotherapy. They were analyzed by univariate and multivariate Cox proportional hazard mode and variables with $\mathrm{P}<0.05$ in both univariate and multivariate analysis were identified as independent prognostic factors. In this study, bilateral $\mathrm{P}$ values less than 0.05 were considered statistically significant.

As the data in this study were obtained from the American cancer registry database, detailed treatment regimens and recurrence data are not available, and there may be some bias in the results. Nevertheless, the analysis based on real data can guide the clinical application of molecular subtype to evaluate prognosis of patients with de novo stage IV breast cancer and provide reference data for clinical diagnosis and treatment. The study was conducted in accordance with the Declaration of Helsinki (as revised in 2013).

\section{Results}

\section{Patient characteristics}

A total of 11,974 de novo stage IV breast cancer patients were included in this study, including 7,100 (59.30\%) patients of $\mathrm{HR}^{+} / \mathrm{HER}^{-}$, $2,093(17.48 \%)$ of $\mathrm{HR}^{+} / \mathrm{HER}^{+}$, $1,139(9.51 \%)$ of $\mathrm{HR}^{-} / \mathrm{HER}^{+}$and $1,642(13.71 \%)$ of $\mathrm{HR}^{-} /$ HER2 ${ }^{-}$. The median age of all patients was 60 years (IQR, 51-70 years), and the age distribution was different among patients with different molecular subtypes $(\mathrm{P}<0.001)$. The distribution of histological type, grade, lymph node stage, surgery, radiotherapy and chemotherapy were all different among patients with different molecular subtypes (all $\mathrm{P}<0.05$; Table 1).

\section{Molecular subtypes and prognosis}

During a median follow-up of 20 months (IQR, 8-37 months), 6,496 (54.25\%) patients died of breast cancer, including 3,732 (52.56\%) patients of $\mathrm{HR}^{+} / \mathrm{HER}^{-}, 933$ (44.58\%) of $\mathrm{HR}^{+} / \mathrm{HER}^{+}, 574(50.40 \%) \mathrm{HR}^{-} / \mathrm{HER}^{+}{ }^{+}$and $1,257(76.55 \%)$ of $\mathrm{HR}^{-} / \mathrm{HER} 2^{-}$. Univariate Cox analysis showed that molecular subtype, age, race, marital status, histological type, grade, lymph node stage, surgery, radiotherapy and chemotherapy were all associated with BCSS. BCSS-related prognostic factors were included in multivariate Cox regression model. Compared to $\mathrm{HR}^{+} /$ HER2 ${ }^{-}$breast cancer patients, $\mathrm{HR}^{+} / \mathrm{HER} 2^{+}$patients had better BCSS ( $\mathrm{HR}=0.81,95 \% \mathrm{CI}: 0.75-0.88, \mathrm{P}<0.001$ ), $\mathrm{HR}^{-} / \mathrm{HER} 2^{-}$patients had worse BCSS (HR $=1.42,95 \%$ CI: $1.29-1.46, \mathrm{P}<0.001)$ and $\mathrm{HR}^{-} / \mathrm{HER}^{+}$patients had no significant difference (HR $=1.03$, 95\% CI: 0.98-1.08, $\mathrm{P}=0.188$ ), as shown in Figure 1. Multivariate Cox analysis showed that age, race, marital status, grade, surgery and chemotherapy were independent prognostic factors for BCSS in patients with de novo stage IV breast cancer (Table 2).

\section{Analysis of single organ metastasis}

Subgroup multivariate Cox regression analysis was performed in patients with single organ metastasis. In patients with bone, lung or liver metastasis, the $\mathrm{HR}^{+}$/ HER2 ${ }^{+}$subtype had a better prognosis than other molecular subtypes. In patients with brain metastasis, there was no statistically significant difference in the prognosis among $\mathrm{HR}^{+} / \mathrm{HER}^{+}, \mathrm{HR}^{+} / \mathrm{HER}^{-}$and $\mathrm{HR}^{-} / \mathrm{HER} 2^{+}$subtypes. Patients with triple negative breast cancer had the worst prognosis in all single organ metastasis subgroups (Table 3, Figures 2,3).

\section{Discussion}

De novo stage IV breast cancer is a breast cancer with distant metastasis at the time of initial diagnosis and is an incurable systemic disease with prognosis closely related to biological characteristics and metastatic site $(10,14)$. Because of distant 
Table 1 Patient characteristics according to tumor subtype

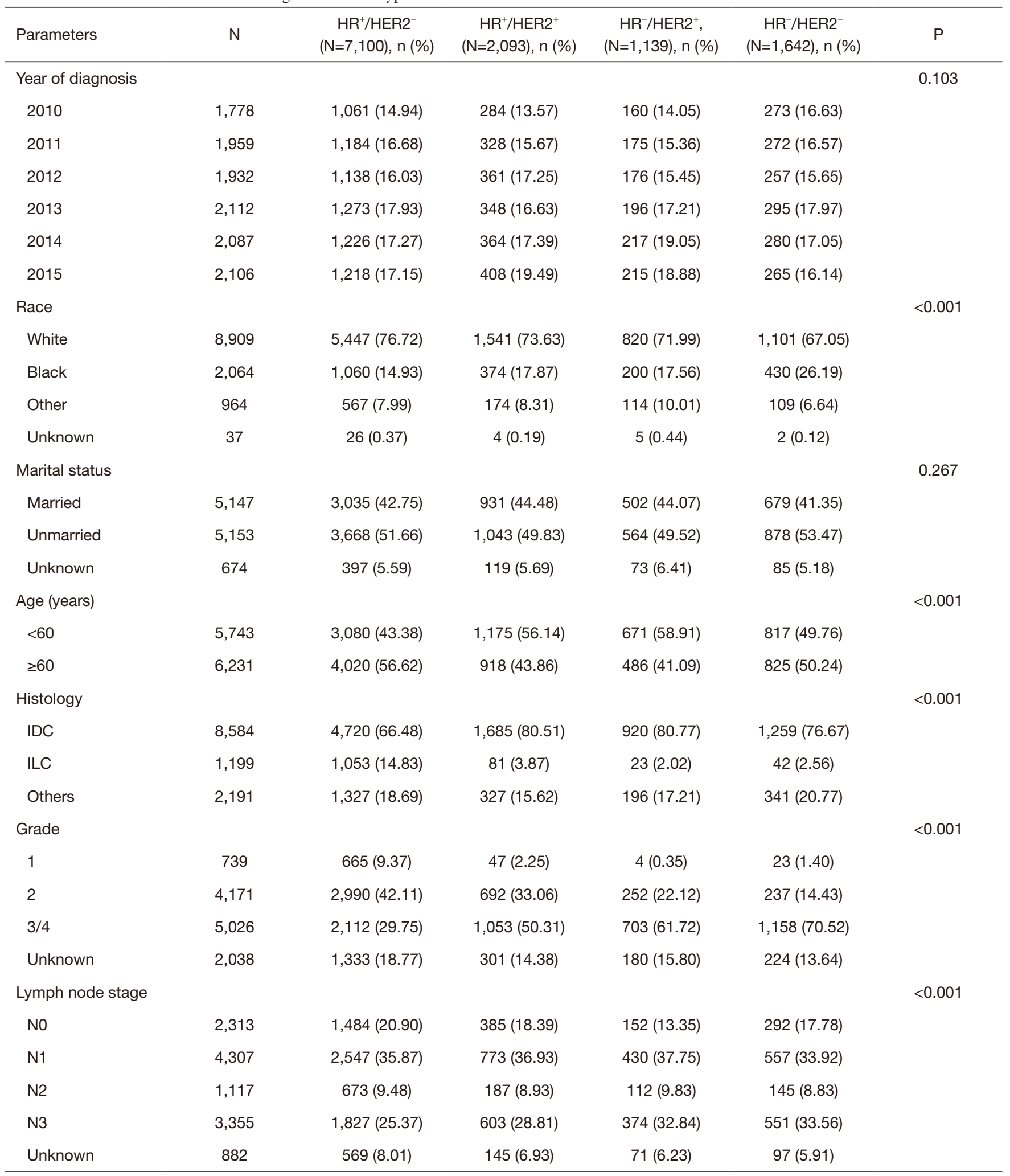

Table 1 (continued) 
Table 1 (continued)

\begin{tabular}{|c|c|c|c|c|c|c|}
\hline Parameters & $\mathrm{N}$ & $\begin{array}{c}\mathrm{HR}^{+} / \mathrm{HER}^{-} \\
(\mathrm{N}=7,100), \mathrm{n}(\%)\end{array}$ & $\begin{array}{c}\mathrm{HR}^{+} / \mathrm{HER}^{+} \\
(\mathrm{N}=2,093), \mathrm{n}(\%)\end{array}$ & $\begin{array}{c}\mathrm{HR}^{-} / \mathrm{HER}^{+}, \\
(\mathrm{N}=1,139), \mathrm{n}(\%)\end{array}$ & $\begin{array}{c}\mathrm{HR}^{-} / \mathrm{HER}^{-} \\
(\mathrm{N}=1,642), \mathrm{n}(\%)\end{array}$ & $P$ \\
\hline Surgery & & & & & & $<0.001$ \\
\hline Yes & 3,561 & $1,939(27.31)$ & $631(30.15)$ & 377 (33.10) & 614 (37.39) & \\
\hline No/unknown & 7,992 & 4,665 (65.70) & $1,422(67.94)$ & 779 (68.39) & $1,126(68.57)$ & \\
\hline Yes & 3,982 & 2,435 (34.30) & 671 (32.06) & 360 (31.61) & $516(31.43)$ & \\
\hline Chemotherapy & & & & & & $<0.001$ \\
\hline All death & 7,351 & $4,160(60.00)$ & $1,042(49.78)$ & $640(56.19)$ & $1,409(86.81)$ & $<0.001$ \\
\hline
\end{tabular}

$\mathrm{HR}^{+}$, hormone receptor (HR) includes estrogen receptor (ER) and progesterone receptor (PR), and $\mathrm{HR}^{+}$is defined as $\mathrm{ER}$ or $\mathrm{PR}$ positive; HER2, human epidermal growth factor receptor-2; IDC, invasive ductal carcinoma; ILC, invasive lobular carcinoma.

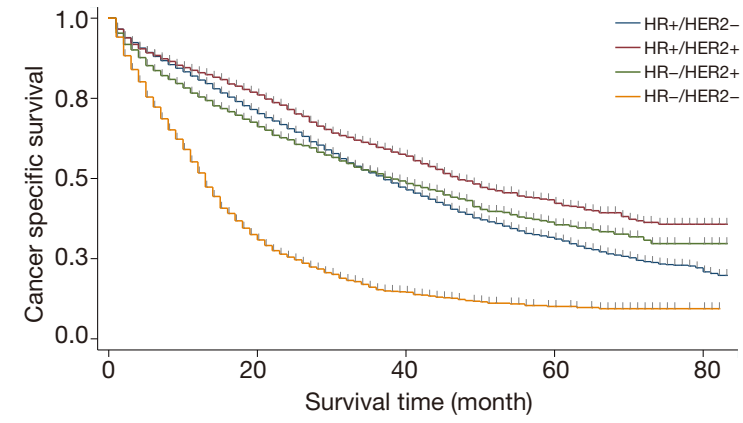

Figure 1 Kaplan-Meier curve for BCSS according to tumor subtype. BCSS, breast cancer specific survival. HR, hormone receptor; HER2, human epidermal growth factor receptor-2.

metastasis, stage IV patients are substantially different from early-stage patients in terms of treatment objectives and strategies. Molecular subtype, which reflects the biological characteristics of the tumor, is of great value in evaluating prognosis and guiding treatment in early-stage breast cancer patients, while its value in de novo stage IV remains unclear. In this study, a large sample case analysis using SEER database showed that molecular subtype was closely related to the prognosis of de novo stage IV breast cancer, in which $\mathrm{HR}^{+} / \mathrm{HER} 2^{+}$had the best prognosis and $\mathrm{HR}^{-} / \mathrm{HER} 2^{-}$ had the worst prognosis, and there were slight differences in the relationship between molecular subtype and prognosis in patients with different metastatic sites.

Breast cancer is a highly heterogeneous disease and initially classified into different genotypes by genetic testing which is a good predictor of prognosis (15-17). Due to the poor availability and accessibility of genetic testing, patients are divided into four immunohistochemical molecular subtypes- $\mathrm{HR}^{+} / \mathrm{HER} 2^{-}, \mathrm{HR}^{+} / \mathrm{HER} 2^{+}, \mathrm{HR}^{-} / \mathrm{HER} 2^{+}$and $\mathrm{HR}^{-} / \mathrm{HER} 2^{-}$, based on the status of ER, PR and HER2 to replace genotyping in clinical evaluation of prognosis and guidance of treatment. $\mathrm{HR}^{+} / \mathrm{HER} 2^{+}$had the best prognosis and $\mathrm{HR}^{-} / \mathrm{HER} 2^{-}$had the worst prognosis in patients with early breast cancer. However, breast cancer subtypes are not associated with prognosis in untreated patient and, in contrast, significantly associated with prognosis in patients with conventional therapy (18). There are significant differences in therapeutic objectives and strategies between early breast cancer and de novo stage IV breast cancer, and the relationship between molecular subtypes and the prognosis of the latter is still unclear.

The results of this study showed that among patients with de novo stage IV breast cancer, patients with $\mathrm{HR}^{+} /$ HER2 ${ }^{+}$subtype had a better prognosis than those with other subtypes while patients with $\mathrm{HR}^{-} / \mathrm{HER}^{-}$subtype had the worst prognosis, which was the same as those with 
Table 2 Analysis of prognostic factors

\begin{tabular}{|c|c|c|c|c|}
\hline \multirow{2}{*}{ Parameters } & \multicolumn{4}{|c|}{ Breast cancer specific survival } \\
\hline & $\mathrm{HR}(95 \% \mathrm{Cl})$ & $\mathrm{P}$ & $\mathrm{HR}(95 \% \mathrm{Cl})$ & $\mathrm{P}$ \\
\hline $\mathrm{HR}^{+} / \mathrm{HER}^{-}$ & 1 (reference) & & 1 (reference) & \\
\hline $\mathrm{HR}^{+} / \mathrm{HER}^{+}$ & $0.76(0.71-0.82)$ & $<0.001$ & $0.81(0.75-0.88)$ & $<0.001$ \\
\hline $\mathrm{HR}^{-} / \mathrm{HER}^{-}$ & $1.39(1.35-1.42)$ & $<0.001$ & $1.42(1.29-1.46)$ & $<0.001$ \\
\hline \multicolumn{5}{|l|}{ Age (years) } \\
\hline$<60$ & 1 (reference) & & 1 (reference) & \\
\hline$\geq 60$ & $1.35(1.28-1.42)$ & $<0.001$ & $1.26(1.20-1.33)$ & $<0.001$ \\
\hline Others & $0.95(0.90-1.00)$ & 0.045 & $0.97(0.92-1.02)$ & 0.227 \\
\hline \multicolumn{5}{|l|}{ Marital status } \\
\hline Married & 1 (reference) & & 1 (reference) & \\
\hline Unmarried & $1.36(1.29-1.44)$ & $<0.001$ & $1.26(1.20-1.33)$ & $<0.001$ \\
\hline \multicolumn{5}{|l|}{ Histology } \\
\hline IDC & 1 (reference) & & 1 (reference) & \\
\hline ILC & $1.01(0.93-1.10)$ & 0.812 & $1.08(0.99-1.18)$ & 0.09 \\
\hline Others & $1.05(1.02-1.09)$ & 0.003 & $0.99(0.96-1.03)$ & 0.716 \\
\hline N1 & $0.96(0.90-1.04)$ & 0.343 & $1.01(0.94-1.09)$ & 0.716 \\
\hline $\mathrm{N} 2$ & $0.98(0.93-1.03)$ & 0.439 & 1.07 (1.01-1.13) & 0.014 \\
\hline N3 & $1.07(1.04-1.10)$ & $<0.001$ & $1.09(1.06-1.11)$ & $<0.001$ \\
\hline \multicolumn{5}{|l|}{ Surgery } \\
\hline No & 1 (reference) & & 1 (reference) & \\
\hline Yes & $0.59(0.56-0.63)$ & $<0.001$ & $0.59(0.56-0.63)$ & $<0.001$ \\
\hline \multicolumn{5}{|l|}{ Radiotherapy } \\
\hline No & 1 (reference) & & 1 (reference) & \\
\hline Yes & $0.92(0.87-0.97)$ & 0.001 & $1.04(0.98-1.09)$ & 0.196 \\
\hline \multicolumn{5}{|c|}{ Chemotherapy } \\
\hline No & 1 (reference) & & 1 (reference) & \\
\hline Yes & $0.79(0.75-0.83)$ & $<0.001$ & $0.70(0.66-0.74)$ & $<0.001$ \\
\hline
\end{tabular}

$\mathrm{HR}$, hazard ratio; $\mathrm{Cl}$, confidence interval; $\mathrm{HR}^{+}$, hormone receptor $(\mathrm{HR})$ includes estrogen receptor (ER) and progesterone receptor (PR), and $\mathrm{HR}^{+}$is defined as ER or PR positive; HER2, human epidermal growth factor receptor-2; IDC, invasive ductal carcinoma; ILC, invasive lobular carcinoma. 
Table 3 Multivariate Cox analysis of tumor subtype and prognosis of patients with single organ metastasis

\begin{tabular}{|c|c|c|c|c|c|c|c|c|c|}
\hline Subtypes & $\mathrm{N}$ & \multicolumn{2}{|c|}{ Bone only $(n=4,599)$} & \multicolumn{2}{|c|}{ Lung only $(n=1,245)$} & \multicolumn{2}{|c|}{ Liver only ( $\mathrm{n}=940$ ) } & \multicolumn{2}{|c|}{ Brain only $(n=174)$} \\
\hline \multicolumn{10}{|l|}{ BCSS } \\
\hline $\mathrm{HR}^{+} / \mathrm{HER}^{-}$ & 7,100 & 1 (reference) & & 1 (reference) & & 1 (reference) & & 1 (reference) & \\
\hline $\mathrm{HR}^{+} / \mathrm{HER}^{+}{ }^{+}$ & 2,093 & $0.83(0.72-0.96)$ & 0.014 & $0.64(0.48-0.87)$ & 0.005 & $0.55(0.41-0.73)$ & $<0.001$ & $1.14(0.60-2.16)$ & 0.688 \\
\hline $\mathrm{HR}^{-} / \mathrm{HER}^{-}$ & 1,642 & $1.43(1.36-1.51)$ & $<0.001$ & $1.46(1.36-1.56)$ & $<0.001$ & $1.41(1.29-1.54)$ & $<0.001$ & $1.26(1.04-1.54)$ & 0.018 \\
\hline \multicolumn{10}{|l|}{ os } \\
\hline $\mathrm{HR}^{+} / \mathrm{HER}^{-}$ & 7,100 & 1 (reference) & & 1 (reference) & & 1 (reference) & & 1 (reference) & \\
\hline $\mathrm{HR}^{+} / \mathrm{HER}^{+}$ & 2,093 & $0.84(0.73-0.96)$ & 0.011 & $0.66(0.50-0.88)$ & 0.004 & $0.56(0.43-0.72)$ & $<0.001$ & $1.05(0.58-1.91)$ & 0.862 \\
\hline
\end{tabular}

HR, hazard ratio; $\mathrm{Cl}$, confidence interval; BCSS, breast cancer specific survival; OS, overall survival; $\mathrm{HR}^{+}$, hormone receptor (HR) includes estrogen receptor (ER) and progesterone receptor (PR), and $\mathrm{HR}^{+}$is defined as ER or PR positive; HER2, human epidermal growth factor receptor-2.
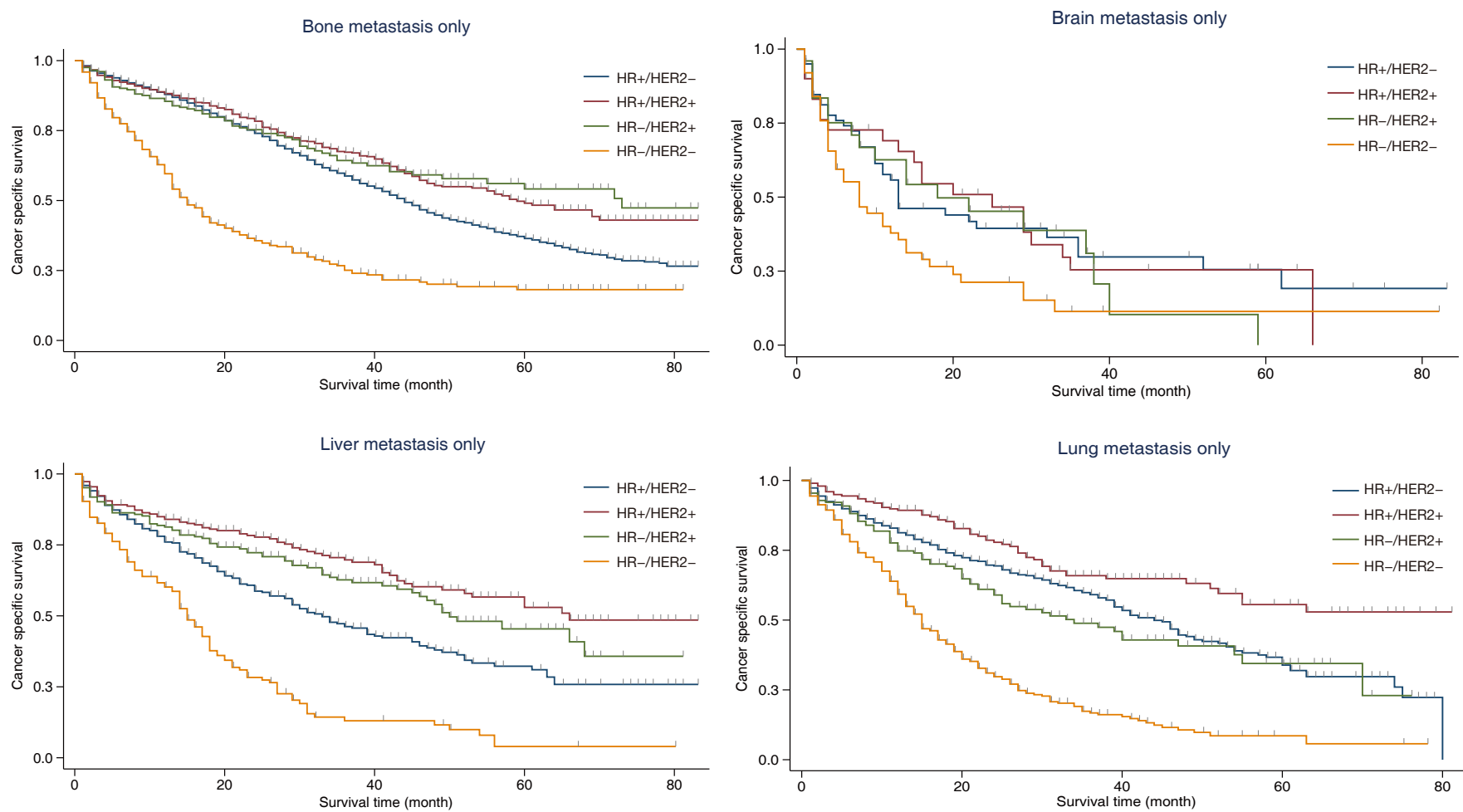

Figure 2 Kaplan-Meier curves for cancer specific survival according to the metastatic site. HR, hormone receptor; HER2, human epidermal growth factor receptor- 2 . 


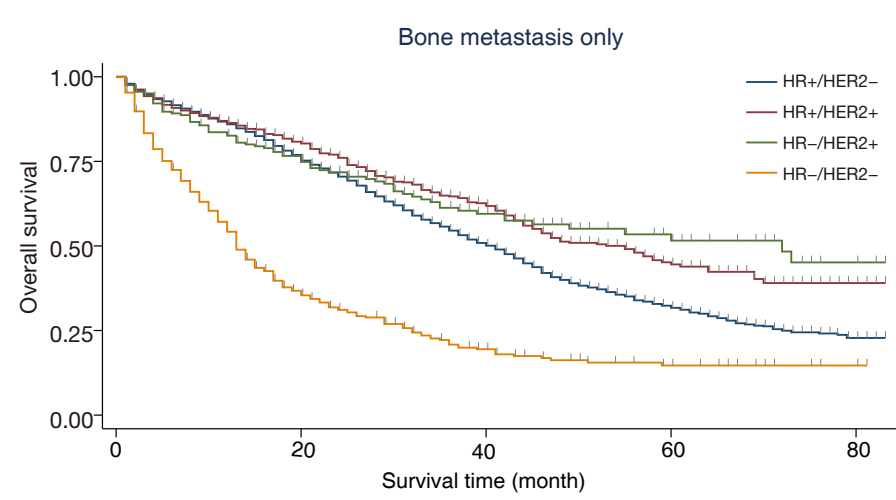

Liver metastasis only

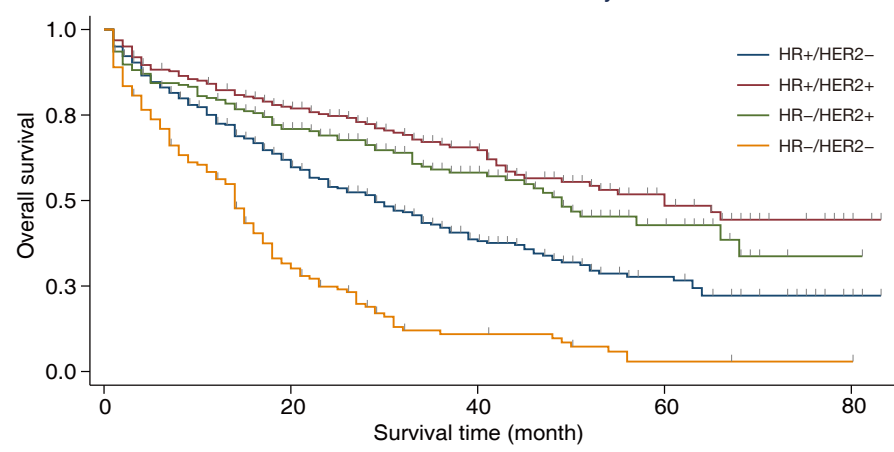

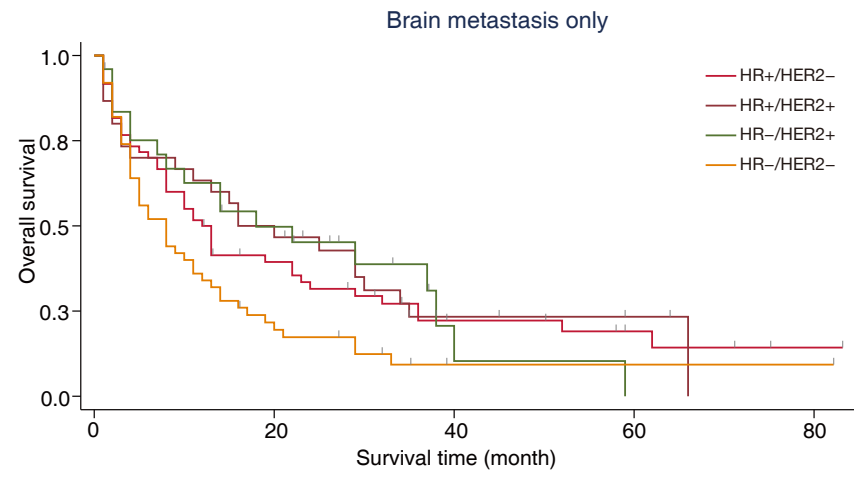

Lung metastasis only

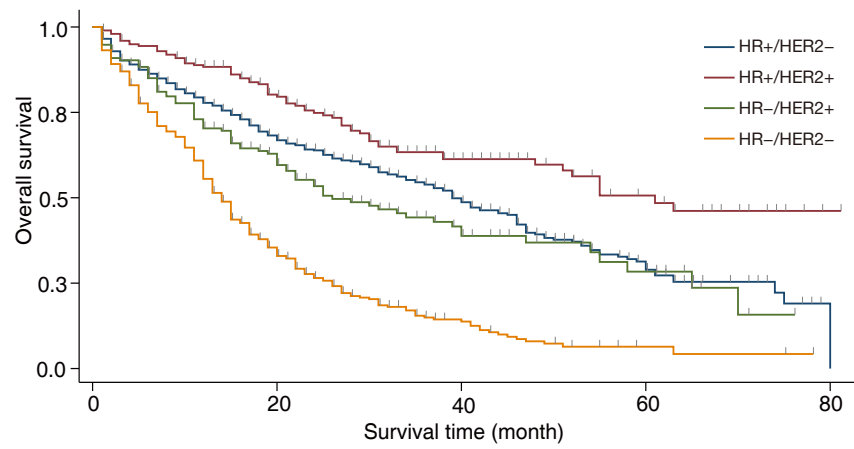

Figure 3 Kaplan-Meier curves for overall survival according to the metastatic site. ER, estrogen receptor.

early breast cancer. However, the relationship between molecular subtype and prognosis was slightly different in patients with different metastatic sites. Comparing patients with the same organ metastasis, we found that the prognosis of $\mathrm{HR}^{-} / \mathrm{HER} 2^{-}$subtype was the worst in patients with bone, liver, lung, or brain metastases, while the prognosis of $\mathrm{HR}^{+} / \mathrm{HER} 2^{+}$subtype was the best in patients with bone, liver, or lung metastases (excluding brain metastases). To a certain extent, molecular subtypes reflect the biological characteristics of tumor and predict the sensitivity of treatment. HR-positive patients are sensitive to endocrine therapy, while HER2-positive can be treated with antiHER2 targeted therapy $(5,8,19)$. The prognosis of $\mathrm{HR}^{+} /$ HER $2^{+}$patients is better than that of other subtypes possibly due to sensitivity to endocrine therapy and anti-HER2 therapy. In contrast, $\mathrm{HR}^{-} / \mathrm{HER} 2^{-}$(triple negative) patients who lack endocrine therapy and anti-HER2 therapy had the worst prognosis (20). Although stage IV breast cancer is incurable, classification based on molecular subtype can provide patients with more choices of treatment to improve survival. In the study, lack of data about detailed treatment and recurrence information from American cancer registry database inevitably cause some bias in the results. However, the analysis based on real data is meaningful for the application of molecular subtype in stage IV breast cancer and provide reference for clinical diagnosis and treatment.

\section{Acknowledgments}

We gratefully acknowledge Dr. Zhengwei Leng for his valuable assistance and insightful suggestions with the experiments. And we would like to thank Yvonne Yi. Qian for her effort in language editing and polishing.

Funding: This work was funded by the Foundation of the Health and Planning Committee of Sichuan province (No. 18PJ005); Foundation of the Department of Science and Technology of Sichuan province (No. 19YYJC0384); Foundation of Pre-research Project of National Natural (Social) Science Foundation of North Sichuan Medical College (CBY19-YZ13); Key Project of Affiliated Hospital of North Sichuan Medical College (2019ZD006).

\section{Footnote}

Reporting Checklist: The authors have completed the STROBE reporting checklist. Available at https://dx.doi. 
org/10.21037/gs-21-32

Conflicts of Interest: All authors have completed the ICMJE uniform disclosure form (available at https://dx.doi. org/10.21037/gs-21-32). The authors have no conflicts of interest to declare.

Ethical Statement: The authors are accountable for all aspects of the work in ensuring that questions related to the accuracy or integrity of any part of the work are appropriately investigated and resolved. The study was conducted in accordance with the Declaration of Helsinki (as revised in 2013).

Open Access Statement: This is an Open Access article distributed in accordance with the Creative Commons Attribution-NonCommercial-NoDerivs 4.0 International License (CC BY-NC-ND 4.0), which permits the noncommercial replication and distribution of the article with the strict proviso that no changes or edits are made and the original work is properly cited (including links to both the formal publication through the relevant DOI and the license). See: https://creativecommons.org/licenses/by-nc-nd/4.0/.

\section{References}

1. Badwe R, Hawaldar R, Nair N, et al. Locoregional treatment versus no treatment of the primary tumour in metastatic breast cancer: an open-label randomised controlled trial. Lancet Oncol 2015;16:1380-8.

2. Cardoso F, Spence D, Mertz S, et al. Global analysis of advanced/metastatic breast cancer: Decade report (20052015). Breast 2018;39:131-8.

3. Truong PT. Local Treatment of the Primary Tumor in Patients Presenting With Stage IV Breast Cancer: A First, and What's Up Ahead. Int J Radiat Oncol Biol Phys 2017;97:443-6.

4. Cardoso F, Senkus E, Costa A, et al. 4th ESO-ESMO International Consensus Guidelines for Advanced Breast Cancer (ABC 4). Ann Oncol 2018;29:1634-57.

5. Harbeck N, Gnant M. Breast cancer. Lancet 2017;389:1134-50.

6. Lane WO, Thomas SM, Blitzblau RC, et al. Surgical Resection of the Primary Tumor in Women With De Novo Stage IV Breast Cancer: Contemporary Practice Patterns and Survival Analysis. Ann Surg 2019;269:537-44.
7. Prat A, Pineda E, Adamo B, et al. Clinical implications of the intrinsic molecular subtypes of breast cancer. Breast 2015;24 Suppl 2:S26-35.

8. Goldhirsch A, Winer EP, Coates AS, et al. Personalizing the treatment of women with early breast cancer: highlights of the St Gallen International Expert Consensus on the Primary Therapy of Early Breast Cancer 2013. Ann Oncol 2013;24:2206-23.

9. Bernstein L, Lacey JV Jr. Receptors, associations, and risk factor differences by breast cancer subtypes: positive or negative? J Natl Cancer Inst 2011;103:451-3.

10. Curigliano G, Burstein HJ, Winer EP, et al. De-escalating and escalating treatments for early-stage breast cancer: the St. Gallen International Expert Consensus Conference on the Primary Therapy of Early Breast Cancer 2017. Ann Oncol 2017;28:1700-12.

11. Tao L, Chu L, Wang LI, et al. Occurrence and outcome of de novo metastatic breast cancer by subtype in a large, diverse population. Cancer Causes Control 2016;27:1127-38.

12. Andre F, Slimane K, Bachelot T, et al. Breast cancer with synchronous metastases: trends in survival during a 14year period. J Clin Oncol 2004;22:3302-8.

13. Cortesi L, Toss A, Cirilli C, et al. Twenty-years experience with de novo metastatic breast cancer. Int J Cancer 2015;137:1417-26.

14. Kennecke H, Yerushalmi R, Woods R, et al. Metastatic behavior of breast cancer subtypes. J Clin Oncol 2010;28:3271-7.

15. Perou CM, Sørlie T, Eisen MB, et al. Molecular portraits of human breast tumours. Nature 2000;406:747-52.

16. Kwa M, Makris A, Esteva FJ. Clinical utility of geneexpression signatures in early stage breast cancer. Nat Rev Clin Oncol 2017;14:595-610.

17. Wirapati P, Sotiriou C, Kunkel S, et al. Meta-analysis of gene expression profiles in breast cancer: toward a unified understanding of breast cancer subtyping and prognosis signatures. Breast Cancer Res 2008;10:R65.

18. Yang SX, Polley EC. Systemic treatment and radiotherapy, breast cancer subtypes, and survival after long-term clinical follow-up. Breast Cancer Res Treat 2019; 175:287-95.

19. Ramakrishna N, Temin S, Chandarlapaty S, et al. Recommendations on disease management for patients with advanced human epidermal growth factor receptor 2-positive breast cancer and brain metastases: American Society of Clinical Oncology clinical practice guideline. J 
Clin Oncol 2014;32:2100-8.

20. Lund MJ, Trivers KF, Porter PL, et al. Race and triple negative threats to breast cancer survival: a population- based study in Atlanta, GA. Breast Cancer Res Treat 2009;113:357-70.

Cite this article as: Hou L, Qiu M, Chen M, Li F, Li J, Deng S, Yang Y, Du Z, Yang H. The association between molecular type and prognosis of patients with stage IV breast cancer: an observational study based on SEER database. Gland Surg 2021;10(6):1889-1898. doi: 10.21037/gs-21-32 